\title{
EORTC QLQ-C30 Health and Quality of Life Rating Scale
}

National Cancer Institute

\section{Source}

National Cancer Institute. EORTC QLQ-C3O Health and Quality of Life Rating Scale. NCI

Thesaurus. Code C120497.

A scale used both for the subjective scoring of a person's overall health, and for their quality of life, that ranges from 1: Very Poor to 7: Excellent. 